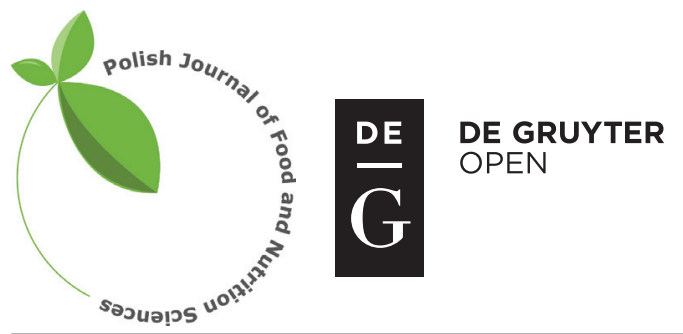

Pol. J. Food Nutr. Sci., 2018, Vol. 68, No. 4, pp. 327-334

DOI: $10.1515 /$ pjfns-2018-0007 http://journal.pan.olsztyn.pl

Original research article

Section: Food Chemistry

\title{
Comparison of the Biological Activity of Crude Polysaccharide Fractions Obtained from Cedrela sinensis Using Different Extraction Methods
}

\author{
Min Hui Oh, Kyung Young Yoon* \\ Department of Food and Nutrition, Yeungnam University, Gyeongsan, Gyeongbuk 38547, Korea
}

Key words: Cedrela sinensis, extraction method, polysaccharides, antioxidant activity, biological activity

Four preparations of crude polysaccharides were obtained from Cedrela sinensis using four methods of extraction, and finally precipitation with ethanol. Hot-water and processes assisted by ultrasound and enzymes (Shearzyme or Viscozyme) were carried out. The yield of polysaccharide fraction extracted with the enzyme-assisted method using Shearzyme (P-EAS) was the highest at $10.53 \%$. All crude saccharides were composed of six monosaccharides including arabinose, galactose, glucose, mannose, rhamnose, and xylose. Crude polysaccharide fraction extracted by hot water showed the highest $\mathrm{DPPH}^{\bullet}$ and $\mathrm{ABTS}^{\bullet+}$ scavenging activities as well as $\alpha$-amylase inhibitory activity. All fractions showed higher retardation effects on glucose and bile acid absorption using the in vitro dialysis system compared to the control (without polysaccharide fraction); specifically, the glucose retardation index of P-EAS was similar to that of carboxymethylcellulose. Overall, crude polysaccharide fractions obtained from C. sinensis can be used as functional ingredients owing to their excellent functional properties.

\section{INTRODUCTION}

Cedrela sinensis, which belongs to the Meliaceae family, is a tall tree that grows in Korea and China and has been used to treat enteritis, dysentery, and itch in oriental medicine [Oh et al., 2015]. Young C. sinensis leaves and sprouts have also been used as functional foods in Korean cuisine for decades. Tree buds, which appear in springtime, are known to contain an abundance of nutrients and antioxidant constituents, such as limonoids, flavonoids and other phenolic compounds, and phytol derivatives [Luo et al., 2000; Park et al., 1996]. In addition, the crude extract of $C$. sinensis was shown to have apoptosis-inducing effects on cancer cells as well as anti-obesity activity due to enhanced lipolysis of differentiated 3T3-L1 adipocytes [Hsu et al., 2003].

Polysaccharides, which are an abundant group of biopolymers, have recently attracted attention owing to their biological effects on living organisms and have been used in the pharmaceuitcal, feed, and food industries [Wang et al., 2012b]. Natural polysaccharides play important roles in numerous biological processes, such as cell-cell communication, embryonic development, and infection of bacteria. Polysaccharides are potentially natural pharmaceuticals and targets for drug design because they have specific biological activities, such as antibacterial activity, anticancer activity, and immunoenhancing effects [Luo et al., 2012]. Bioactive polysaccharides have also been widely studied as radical scavengers

\footnotetext{
* Corresponding Author: Tel,: +82-53-810-2878; Fax: +82-53-810-4768

E-mail: yoonky2441@ynu.ac.kr
}

in the prevention of oxidative damage in human cells [Wang et al., 2012a].

In general, polysaccharides are bound to other components like protein, lipids, lignin, and some inorganic minerals in cells. Thus, polysaccharide extraction and isolation from various sources is the most important task in the investigation and application of bioactive polysaccharides. The extraction technique used may significantly influence the yield, physical characteristics, and biological activities of the polysaccharides. Hot-water extraction (HWE), ultrasonic-assisted extraction (UAE), microwave-assisted extraction, enzyme-assisted extraction (EAE), maceration, and heat reflux with solvents are the main methods for polysaccharide extraction from natural resources [Fan et al., 2015]. HWE is traditionally used because it is a convenient, fast, environment-friendly, and economical technology [Liu et al., 2016]. UAE has been widely used to extract bioactive components from various plant materials based on mass transfer intensification, cell collapse, increased penetration, and capillary effects [Yin et al., 2016]. EAE can be used to release natural functional compounds from plant materials, owing to cell wall degradation that facilitates polysaccharide dissolution into the solvent [Pan et al., 2015].

In this study, crude polysaccharides were extracted from C. sinensis by various extraction methods and their health-related properties were measured in order to improve their availability to functional food materials. The crude polysaccharide fractions from $C$. sinensis were extracted using hot water, ultrasonic-assisted, and enzyme-assisted methods. Biological activities such as antioxidant activity, $\alpha$-amylase in- 
hibitory activity, and glucose and bile acid retardation effects of the polysaccharides isolated using four extraction methods were compared in this study.

\section{MATERIAL AND METHOD}

\section{Materials}

C. sinensis was purchased from the National Agricultural Cooperative Federation (Sangju, Korea) and freeze-dried. It was ground to a fine power using a food mixer (M-1211; Starion, Busan, South Korea) and then stored in a deep freezer (MDF-435; Sanyo, Tokyo, Japan) at $-40^{\circ} \mathrm{C}$. Shearzyme Plus and Viscozyme L (Novozymes A/S, Bagsvaerd, Denmark) are both commercial enzymes which were used in this study for enzyme-assisted extraction.

\section{Hot-water extraction (HWE)}

A dried ground sample of $C$. sinensis (5 g) was mixed with $100 \mathrm{~mL}$ of distilled water in an Erlenmeyer flask. The mixture was placed in a shaking water bath (BS-11, JeioTech, Seoul, Korea) at $80^{\circ} \mathrm{C}$ for $3 \mathrm{~h}$. After extraction, the suspension was filtered and centrifuged at $12,000 \times g$ for $20 \mathrm{~min}$ in a Supra-21K Centrifuge (Hanil, Incheon, Korea). The supernatant was collected and the residue was processed again twice as described above, and the extract was lyophilized with the use of FD8512 Freeze Dryer (IlshinBioBase, Gyeonggi-do, Korea).

\section{Ultrasonic-assisted extraction (UAE)}

A ground sample of $C$. sinensis (5 g) was extracted with distilled water $(1: 20, \mathrm{w} / \mathrm{v})$ in an Erlenmeyer flask $(500 \mathrm{~mL})$. The flask was placed in an ultrasonic bath (5510-DTH, Brason, Danbury, CT, USA), which was circulated by water, set at $45^{\circ} \mathrm{C}$, and an ultrasound power of $495 \mathrm{~W}$ for $45 \mathrm{~min}$. The mixture was centrifuged at $12,000 \times g$ for $20 \mathrm{~min}$, and supernatant was collected and freeze-dried.

\section{Enzyme-assisted extraction (EAE)}

A dried ground sample of $C$. sinensis $(5 \mathrm{~g})$ was mixed with $100 \mathrm{~mL}$ of $0.1 \mathrm{~N}$ acetate buffer $(\mathrm{pH} 4.5)$, and $1 \%(\mathrm{v} / \mathrm{w})$ of the enzyme preparation (Viscozyme or Shearzyme) was added to the mixture. The mixture was incubated in a shaking water bath (BS-11, JeioTech, Seoul, Korea) at $100 \mathrm{rpm}$ and $50^{\circ} \mathrm{C}$ for $120 \mathrm{~min}$, and the temperature was then rapidly increased to $100^{\circ} \mathrm{C}$ for $10 \mathrm{~min}$ to inactivate the enzyme. The reaction mixture was centrifuged at $12,000 \times g$ for $20 \mathrm{~min}$, and supernatant was collected and freeze-dried.

\section{Preparation of crude polysaccharide fractions}

The crude polysaccharide fractions were separated from each extract obtained by different methods as previously described from He et al. [2016] with slight modification. The freeze-dried extract was dissolved in 95\% ethanol and placed at room temperature for $5 \mathrm{~h}$. The polysaccharide precipitate was obtained by centrifugation at $12,000 \times g$ for $20 \mathrm{~min}$, washed three times with ethanol, and freeze-dried. Crude polysaccharide fractions obtained by HWE, UAE, and EAE using Shearzyme and Viscozyme were named as P-HW (crude polysaccharide fraction extracted by hot water), P-UA (crude polysaccharide fraction obtained by UAE),
P-EAS (crude polysaccharide fraction obtained by EAE using Shearzyme), and P-EAV (crude polysaccharide fraction obtained by EAE using Viscozyme), respectively. The yield of crude polysaccharide fraction was calculated as a percentage of the weight of $C$. sinensis powder used in the extraction.

\section{Monosaccharide composition}

Carbohydrate analysis was performed as described by Gulbrandsen et al. [2015] with slight modification. A polysaccharide fraction $(0.2 \mathrm{~g})$ was hydrolyzed with $3 \mathrm{~mL}$ of $72 \%$ $\mathrm{H}_{2} \mathrm{SO}_{4}$ at $45^{\circ} \mathrm{C}$ for $1 \mathrm{~h}$ and then diluted with $84 \mathrm{~mL}$ of distilled water. The hydrolysates were rehydrolyzed at $121^{\circ} \mathrm{C}$ and neutralized to $\mathrm{pH} 7$ with $2 \mathrm{~N}$ sodium hydroxide solution. The resulting supernatant was filtered ( $0.2 \mu \mathrm{m}$ filter). Thus obtained sample was analyzed by a high-performance anion-exchange chromatography system (HPAEC, Dionex ICS-5000, Thermo Scientific, Sunnyvale, CA, USA) equipped with a CarboPac PA-1 column $(250 \times 4 \mathrm{~mm}$, Dionex, Thermo Scientific) . The monosaccharides were eluted from column with $18 \mathrm{mM}$ $\mathrm{NaOH}$ at a flow rate of $1.0 \mathrm{~mL} / \mathrm{min}$. Arabinose, galactose, glucose, mannose, rhamnose, and xylose used as standards were purchased from Sigma Chemical Co. (USA). The content of each monosaccharide was calculated from the calibration curve obtained using each standard.

\section{Antiradical activity - DPPH assay}

The ability of crude polysaccharide fraction to scavenge 2,2-diphenyl-1-picrylhydrazyl (DPPH) radicals was determined as described by Kim et al. [2013]. Each sample $(0.5 \mathrm{~mL})$ was mixed with $1 \mathrm{~mL}$ of $0.2 \mathrm{mM}$ DPPH solution in a test tube. The mixtures were then vortexed and incubated for $20 \mathrm{~min}$ at $37^{\circ} \mathrm{C}$ and DPPH radical scavenging activity was calculated as a percentage of DPPH discoloration by measuring the absorbance at $520 \mathrm{~nm}$ (U-2900, Hitachi, Tokyo, Japan).

\section{Antiradical activity - ABTS assay}

The ability of crude polysaccharide fraction to scavenge 2,2'-azino-bis(3-ethylbenzothiazoline-6-sulfonic acid $\left(\mathrm{ABTS}^{\cdot+}\right.$ ) radicals was measured using the method described by Kim et al. [2013]. Each extract $(50 \mu \mathrm{L})$ was added to $3 \mathrm{~mL}$ of $\mathrm{ABTS}^{\cdot+}$ solution, which was prepared by mixing $0.7 \mathrm{mM}$ $\mathrm{ABTS}^{-+}$solution and $2.45 \mathrm{mM}$ potassium persulfate. The mixtures were incubated in the dark for $6 \mathrm{~min}$ at room temperature, and absorbance was then measured at $734 \mathrm{~nm}$ using a spectrophotometer (U-2900, Hitachi, Tokyo, Japan). The ABTS ${ }^{\bullet+}$ radical scavenging activity was calculated as follows:

$$
\begin{array}{r}
\mathrm{ABTS}^{\cdot+} \text { radical scavenging activity }(\%)= \\
=\left(1-\mathrm{A}_{\text {sample }} / \mathrm{A}_{\text {control }}\right) \times 100
\end{array}
$$

where: $\mathrm{A}_{\text {sample }}$ is the absorbance with the test sample and $\mathrm{A}_{\text {blank }}$ is the absorbance with distilled water.

\section{$\alpha$-Amylase inhibitory activity}

$\alpha$-Amylase inhibitory activity of crude polysaccharide fraction was determined according to Telagari \& Hullatti [2015], with some modifications. The reaction time and temperature were changed accordingly due to the increase in the amount of sample solution. In other words, a reaction mixture con- 
taining $40 \mu \mathrm{L}$ of the polysaccharide solution, at varying concentrations, $50 \mu \mathrm{L}$ phosphate buffer (100 mM, pH 6.8), and $100 \mu \mathrm{L} \alpha$-amylase ( $1 \mathrm{unit} / \mathrm{mL}$; Sigma Chemical Co.) was preincubated at $20^{\circ} \mathrm{C}$ for $10 \mathrm{~min}$. Then, $100 \mu \mathrm{L}$ of $1 \%$ soluble starch (100 mM phosphate buffer, $\mathrm{pH}$ 6.8) was added as a substrate and the mixture was further incubated for $10 \mathrm{~min}$ at $20^{\circ} \mathrm{C}$. DNS color reagent solution $(100 \mathrm{~mL} ; 96 \mathrm{mM}$ 3,5-dinitrosalicylic acid, 5.31 M sodium phosphate tartrate in $2 \mathrm{M} \mathrm{NaOH}$ ) was then added and the mixture was boiled at $90^{\circ} \mathrm{C}$ for $15 \mathrm{~min}$. Finally, $900 \mu \mathrm{L}$ of distilled water was added and the mixture was vortexed. The absorbance was measured at $540 \mathrm{~nm}$ using a microplate reader $(\mathrm{EPOCH}$, BioTek Instrument, Inc., Winooski, VT, USA). Acarbose (Sigma Chemical Co.) at various concentrations was used as a positive control. The change of absorbance was monitored before and after incubation. Percent inhibitory activity was calculated using the following formula:

$$
\text { Inhibitory activity }(\%)=\left(1-\mathrm{A}_{\text {sample }} / \mathrm{A}_{\text {blank }}\right) \times 100
$$

where: $\mathrm{A}_{\text {sample }}$ is the absorbance with the test sample and $\mathrm{A}_{\text {blank }}$ is the absorbance with distilled water.

\section{Determination of the glucose retardation index (GRI)}

GRIs were evaluated as previously described by Im \& Yoon [2015]. Dialysis membrane (Sigma, D7884), with a cut off molecular weight of 1,200 Da, was immersed in a $0.1 \%$ sodium azide solution for $10 \mathrm{~h}$ and filled with $6 \mathrm{~mL}$ of $0.1 \%$ sodium azide solution containing $36 \mathrm{mg}$ of glucose with or without (control) $0.2 \mathrm{~g}$ of the polysaccharide fraction; each sample had previously been hydrated in $0.1 \%$ sodium azide solution for $14 \mathrm{~h}$. Each bag was transferred into a reservoir containing $100 \mathrm{~mL}$ of a $0.1 \%$ sodium azide solution, and dialysis was performed at $37^{\circ} \mathrm{C}$ for $2 \mathrm{~h}$. Dialysate $(1 \mathrm{~mL})$ was collected after $30,60,90$, and $120 \mathrm{~min}$ in order to determine the glucose content. Glucose content in the dialysate was analyzed using the dinitrosalicylic acid (DNS) method previously described by Miller [1959]. The GRI values were then calculated according to the following equation (3):

$$
\begin{array}{r}
\text { GRI value }(\%)=100-\left(\frac{\text { Total glucose diffused from bag }}{\text { Total glucose diffused from bag }}\right. \\
\left.\frac{\text { with crude polysaccharide }}{\text { without crude polysaccharide }}\right) \times 100
\end{array}
$$

To compare the effect of crude polysaccharide fractions on glucose with standard dietary fiber, carboxymethylcellulose (CMC) (Sigma Chemical Co.) was used as a positive control. Sodium azide solution containing glucose without the polysaccharide fraction was used as a negative control.

\section{Determination of bile acid retardation index (BRI)}

Bile acid dialysis retardation indices (BRIs) were used to monitor the effect of crude polysaccharide fractions on sterol metabolism. BRI values were measured using the same method as that used for GRIs described above [Im \& Yoon, 2015]. Dialysis bags were loaded with phosphate buffer (50 mM, pH 7.0), containing $0.1 \%$ sodium azide and $15 \mathrm{mM}$ taurocholic acid (control) or $0.2 \mathrm{~g}$ of sample, and hydrated for $14 \mathrm{~h}$ in buffered taurocholate-containing solution. Bags were transferred into reservoirs containing phosphate buffer (50 mM, pH 7.0) with $0.1 \%$ sodium azide and dialysis was performed at $37^{\circ} \mathrm{C}$ for $5 \mathrm{~h}$ with stirring. Dialysate $(2 \mathrm{~mL})$ was collected after $30 \mathrm{~min}$, and 1,2 , and $5 \mathrm{~h}$ in order to determine bile acid content. Bile acid content in the dialysate was determined by measuring taurocholic acid content as described by Boyd et al. [1966]. BRI values were calculated using the following equation (4):

$$
\begin{array}{r}
\text { BRI value }(\%)=100-\left(\frac{\text { Total bile acid diffused from bag }}{\text { Total bile acid diffused from bag }}\right. \\
\left.\frac{\text { with crude polysaccharide }}{\text { without crude polysaccharide }}\right) \times 100
\end{array}
$$

To compare the effect of crude polysaccharide fractions on bile acid with standard dietary fiber, carboxymethylcellulose (CMC) (Sigma Chemical Co.) was used as a positive control. Sodium azide solution containing taurocholic acid without the polysaccharide fraction was used as a negative control.

\section{Statistical analysis}

Results were expressed as mean \pm standard deviations of triplicate experiments. Multivariate analysis of variance (ANOVA) was performed using SPSS ver. 18.0 (Chicago, IL, USA). Significant differences between mean values were identified using Duncan's multiple range test. The level of significance was at $P<0.05$.

\section{RESULTS AND DISCUSSION}

\section{Yield of crude polysaccharide fractions and their monosaccharide compositions}

The yield of crude polysaccharide fractions obtained by the four extraction methods and composition of polysaccharides are shown in Table 1. Yields of P-HW, P-UA, P-EAS, and P-EAV were 9.7 $\pm 2.1,7.7 \pm 1.8,10.5 \pm 1.3$, and $6.0 \pm 0.3 \%$, respectively. The significantly higher yield of P-EAS than that of P-EAV $(P<0.05)$ suggested that Shearzyme degraded the cell wall of $C$. sinensis more efficiently than Viscozyme. Shearzyme, from Aspergillus oryzae, mainly shows endo-1,4- $\beta$-xylanase activity and may also have cellulase, xylanase, and $\beta$-glucanase activities, while Viscozyme is a multifunctional enzyme that contains hemicellulase, $\beta$-gluconase, arabinase, and xylanase [Oh et al., 2015].

All crude saccharides were composed of six monosaccharides, including rhamnose, arabinose, galactose, glucose, mannose, and xylose. Galactose content was the highest in the polysaccharides $(24.6 \pm 2.8,25.8 \pm 1.2,25.4 \pm 2.4$, and $24.0 \pm 0.6 \mathrm{~g} / 100 \mathrm{~g}$ of P-HW, P-UA, P-EAS, and P-EAV, respectively), followed by arabinose $(17.0 \pm 3.6,15.2 \pm 0.8$, 21.4 \pm 2.8 , and $12.4 \pm 0.2 \mathrm{~g} / 100 \mathrm{~g}$ of P-HW, P-UA, P-EAS, and P-EAV, respectively), with xylose content being the lowest. The major monosaccharides of polysaccharides extracted from Hohenuehelia serotine using the same extraction methods as in the present study, were glucose and mannose 
TABLE 1. The yield of crude polysaccharide fractions of $C$. sinensis and monosaccharide composition of polysaccharides.

\begin{tabular}{|c|c|c|c|c|c|c|c|}
\hline \multirow{2}{*}{ Fraction } & \multirow{2}{*}{ Yield $(\%)$} & \multicolumn{6}{|c|}{ Monosaccharide composition (g/100 g) } \\
\hline & & Arabinose & Galactose & Glucose & Mannose & Rhamnose & Xylose \\
\hline P-HW & $9.7 \pm 2.1^{\mathrm{a}}$ & $17.0 \pm 3.6^{\mathrm{bB}}$ & $24.6 \pm 2.8^{\mathrm{bA}}$ & $14.6 \pm 1.6^{\mathrm{aB}}$ & $1.6 \pm 0.4^{\mathrm{aC}}$ & $2.4 \pm 0.3^{\mathrm{cC}}$ & $0.2 \pm 0.0^{\mathrm{bC}}$ \\
\hline P-UA & $7.7 \pm 1.8^{\mathrm{ab}}$ & $15.2 \pm 0.8^{\mathrm{cB}}$ & $25.8 \pm 1.2^{\mathrm{aA}}$ & $2.8 \pm 0.1^{\mathrm{cC}}$ & $1.4 \pm 0.1^{\mathrm{D}}$ & $2.6 \pm 0.2^{\mathrm{bC}}$ & $0.2 \pm 0.0^{\mathrm{bE}}$ \\
\hline P-EAS & $10.5 \pm 1.3^{\mathrm{a}}$ & $21.4 \pm 2.8^{\mathrm{aB}}$ & $25.4 \pm 2.4^{\mathrm{abA}}$ & $2.8 \pm 0.8^{\mathrm{cCD}}$ & $0.6 \pm 0.3^{\mathrm{bD}}$ & $5.2 \pm 0.4^{\mathrm{cC}}$ & $0.1 \pm 0.0^{\mathrm{cD}}$ \\
\hline P-EAV & $6.0 \pm 0.3^{\mathrm{b}}$ & $12.4 \pm 0.2^{\mathrm{dB}}$ & $24.0 \pm 0.6^{\mathrm{bA}}$ & $3.2 \pm 0.4^{\mathrm{bD}}$ & $0.8 \pm 0.2^{\mathrm{bE}}$ & $7.2 \pm 0.2^{\mathrm{aC}}$ & $0.4 \pm 0.1^{\mathrm{aE}}$ \\
\hline
\end{tabular}

P-HW, crude polysaccharide fraction extracted by hot water; P-UA, crude polysaccharide fraction after ultrasonic-assisted extraction; P-EAS, crude polysaccharide fraction after enzyme-assisted extract using Shearzyme; P-EAV, crude polysaccharide fraction after enzyme-assisted extraction using Viscozyme. Data are expressed as the mean \pm standard deviation $(n=3)$. Values with different small letters in the same column are significantly different $(\mathrm{P}<0.05)$. Values with different capital letters in the same row are significantly different $(\mathrm{P}<0.05)$.

[Li \& Wang, 2016], which was inconsistent with the present results. Zhu et al. [2016] reported that polysaccharides from Cordyceps gunnii mycelia were mainly composed of mannose, glucose, and galactose, with galactose content being the highest regardless of the extraction method used, which was consistent with the results of the present study. These results suggest that the different methods of extraction did not affect monosaccharide composition of the crude polysaccharide fractions, although there was a slight difference in monosaccharide contents. The results also suggest the cell wall of C. sinensis is mainly composed of arabinogalactan. Arabinogalactans are one of the major components of the plant cell wall and are present in a wide range of plants [Bartels et al., 2017]. As a result of their potent biological activity, immunopotentiation properties, and unique solution properties, this peculiar dietary fiber has received increased attention as a clinically useful nutraceutical material [Kelly, 1999].

\section{Antioxidant activity}

Numerous methods are used to evaluate antioxidant activities of natural compounds in foods or biological systems.
ABTS and DPPH assays are commonly used to assess antioxidant activity of phenolic compounds as well as natural plant extracts in vitro [Shalaby \& Shanab, 2013; Li et al., 2017]. Both assays were also successfully used to determine the antioxidant activity of polysaccharide fractions isolated from edible plants [Rout \& Banerjee, 2007; Lin et al., 2009].

DPPH assay was used to determine the proton-scavenging activity of the polysaccharide fractions (P-HW, P-UA, PEAS, and P-EAV) extracted from $C$. sinensis using the four methods. The dose-response curves for the four tested samples are shown in Figure 1A. P-HW showed the highest radical scavenging activity at all concentrations. At a concentration of $800 \mu \mathrm{g} / \mathrm{mL}$, the DPPH radical scavenging activities of P-HW, P-UA, P-EAS, and P-EAV were $62.3 \pm 1.2,47.7 \pm 1.7$, $55.8 \pm 3.9$, and $50.3 \pm 3.6 \%$, respectively. Fu et al. [2010] reported that polysaccharides extracted with hot water showed higher DPPH radical scavenging activity than those extracted by ultrasonic treatment, which was consistent with our results. This suggests that hot water treatment induces the extraction of substances with antiradical activity, such as polyphenols as well as soluble polysaccharides, and is consistent with find-
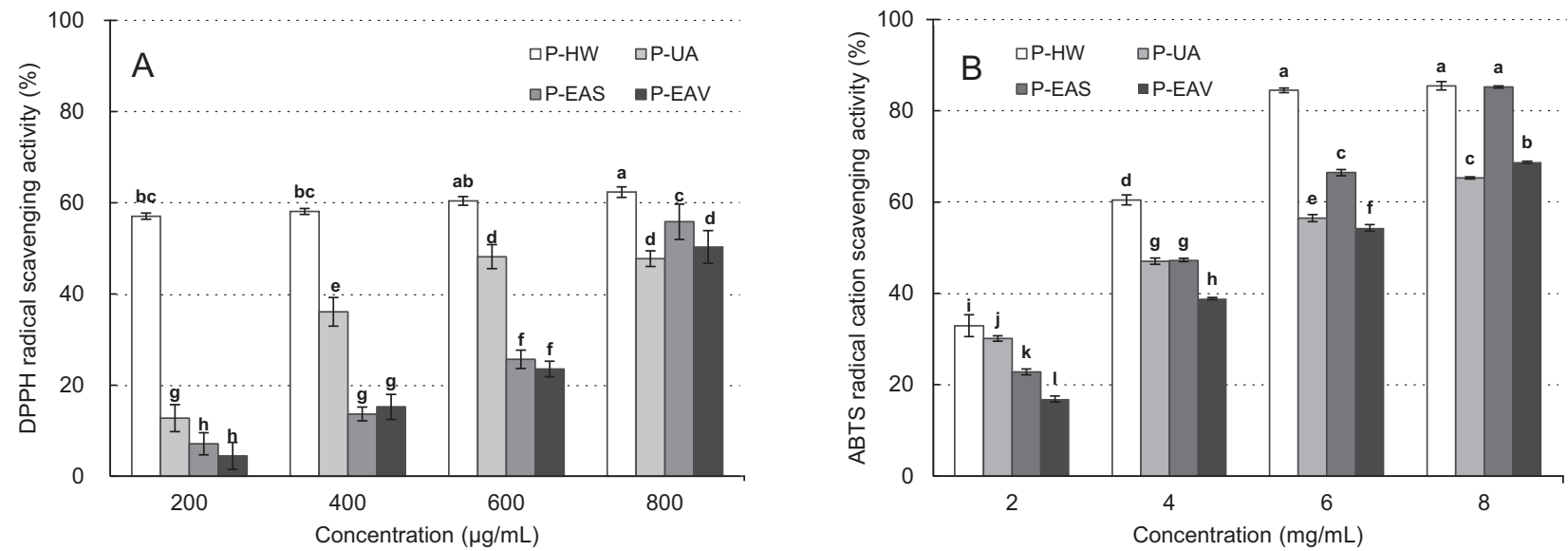

FIGURE 1. Antiradical activity of the crude polysaccharide fractions extracted from C. sinensis determined using DPPH (A) and ABTS assay (B). P-HW, crude polysaccharide fraction extracted by hot water; P-UA, crude polysaccharide fraction after ultrasonic-assisted extraction; P-EAS, crude polysaccharide fraction after enzyme-assisted extract using Shearzyme; P-EAV, crude polysaccharide fraction after enzyme-assisted extraction using Viscozyme.

The results represent mean and standard deviation $(\mathrm{n}=3)$. Values with different letters are significantly different $(\mathrm{P}<0.05)$. 
ings of other authors [Oh \& Yoon, 2017; Sangeethapriya \& Siddhuraju, 2014].

The ABTS assay is a useful method for measuring the antioxidant activities of natural compounds in food or biological systems. Blue-green ABTS radical cation is decolorized by antioxidants and the extent of decolorization is proportional to the antioxidant activity. Figure $1 \mathrm{~B}$ shows the scavenging activity towards ABTS radical cation. All crude polysaccharide fractions exhibited scavenging activity towards ABTS ${ }^{++}$ at all tested concentrations in a dose-dependent manner. The ABTS ${ }^{*+}$ scavenging activity of all samples was more than $50 \%$ at $6 \mathrm{mg} / \mathrm{mL}$; at a concentration of $8 \mathrm{mg} / \mathrm{mL}$, ABTS ${ }^{++}$ scavenging activities of P-HW, P-UA, P-EAS, and P-EAV were $85.5 \pm 0.9,65.3 \pm 0.2,85.2 \pm 0.2$, and $68.8 \pm 0.2 \%$, respectively. Among the four polysaccharide fractions, antioxidant activity of P-HW was significantly higher than that of the others at all concentrations (except for P-EAS at $8 \mathrm{mg} / \mathrm{mL}$ ), while P-EAV showed the lowest radical scavenging activity at all concentrations tested. The results suggest that hot water is most effective at extracting functional substances which contribute to the $\mathrm{ABTS}^{\cdot+}$ scavenging ability, which is in accordance with findings of other authors [Shalaby \& Shanab, 2013].

The radical scavenging abilities of the polysaccharide fractions were generally related to the presence of reductones, which may react with free radicals by donating hydrogen atoms [Chen et al., 2012]. This suggests that the radical scavenging activity of the polysaccharides extracted from C. sinensis, particularly P-HW, may be attributable to a strong hydrogen-donating ability.

\section{$\alpha$-Amylase inhibitory activity}

In the digestive tract, $\alpha$-amylase enzyme starts the process of carbohydrate digestion by hydrolysis of 1,4-glycosidic bonds of alpha-linked polysaccharides (starch, glycogen) to maltose and glucose, leading to postprandial hyperglycemia. An $\alpha$-amylase inhibitor is thus useful for controlling hyperglycemia as it delays carbohydrate digestion, reducing postprandial plasma glucose levels [Telagari \& Hullatti, 2015]. Acarbose is an inhibitor of $\alpha$-amylase and commonly used to decrease glucose absorbance by reducing the production of $\alpha$-amylase in the small intestine. However, acarbose shows some disadvantages, such as an increased risk of gastrointestinal problems, inconvenient dosing, and high cost [Shori, 2015]. Many medicinal plants have been investigated for their ability to inhibit glucose production from carbohydrates in the intestine or glucose absorption in the gut [Horii et al., 1986].

The $\alpha$-amylase inhibitory activity of the four polysaccharide fractions is shown in Table 2. The inhibitory activity of crude polysaccharides increased significantly at an increasing concentration of fractions; from 18.06 \pm 0.46 $-53.78 \pm 0.20 \%(0.5 \mathrm{mg} / \mathrm{mL})$ to $52.26 \pm 0.23-86.92 \pm 0.58 \%$ $(2.0 \mathrm{mg} / \mathrm{mL})$. At all concentrations, P-HW showed the highest inhibitory activity among the samples; more specifically the activity of P-HW was $86.92 \pm 0.58 \%$ at a concentration of $2.0 \mathrm{mg} / \mathrm{mL}$, which was equivalent to $95 \%$ of that of the positive control, acarbose.

Ou et al. [2001] reported that fibers from natural food could decrease postprandial blood glucose levels by hindering glucose diffusion, retarding glucose absorption, and in- hibiting carbohydrate-hydrolyzing enzymes. Natural enzyme inhibitors may offer an effective strategy for treating postprandial hyperglycemia due to minimized abdominal side effects induced from excessive inhibition of $\alpha$-glucosidase by synthetic drugs [Sangeethapriya \& Siddhuraju, 2014]. Our results therefore indicate that polysaccharides obtained from C. sinensis, particularly P-HW, may decrease the $\alpha$-amylase activity, and may thus be potential therapeutic agents for the management of postprandial hyperglycemia.

\section{Inhibitory effect of crude polysaccharide fractions on glucose diffusion}

The GRI is a valuable in vitro index for predicting the effect of dietary fiber on the retardation of glucose absorption in the gastrointestinal tract. Table 3 presents the effects of crude polysaccharide fractions extracted from $C$. sinensis by different methods on glucose diffusion relative to the effects of CMC and a control (without crude polysaccharide fraction). As dialysis time was extended from 30 to $120 \mathrm{~min}$, glucose concentrations in the dialysates containing crude polysaccharide fractions increased from $5.32 \pm 0.50-5.48 \pm 0.45 \mathrm{mg} / 100 \mathrm{~mL}$ (at $30 \mathrm{~min}$ ) to $16.68 \pm 1.52-23.22 \pm 1.08 \mathrm{mg} / 100 \mathrm{~mL}$ (at $120 \mathrm{~min}$ ). Glucose concentrations in the dialysates of CMC and control reached $5.28 \pm 0.38$ and $6.08 \pm 0.50 \mathrm{mg} / 100 \mathrm{~mL}$ (at $30 \mathrm{~min}$ ) and $18.07 \pm 2.56$ and $27.87 \pm 1.76 \mathrm{mg} / 100 \mathrm{~mL}$ (at $120 \mathrm{~min}$ ), respectively. When compared with the control, all crude polysaccharide fractions significantly decreased the amount of diffused glucose in dialysate across the dialysis bag $(P<0.05)$. In turn, for P-EAS (after $30 \mathrm{~min}$ of dialysis) and P-EAS and P-EAV (after 60 min of dialysis), and P-EAV (after 90 min of dialysis) there were no significant differences in glucose concentrations in the dialysates when compared to the CMC.

The GRIs of crude polysaccharides were $9.87-12.50 \%$ after 30 min of dialysis, and the GRI values of all samples except P-HW reached a maximum after $60 \mathrm{~min}$ of dialysis. GRI showed the highest value for P-EAS with $63.76 \%$ followed by CMC

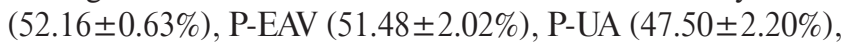

TABLE 2. $\alpha$-Amylase inhibitory activity of crude polysaccharide fractions extracted from $C$. sinensis.

\begin{tabular}{l|c|c|c|c}
\hline \multirow{2}{*}{ Fraction } & \multicolumn{4}{|c}{ Sample concentration $(\mathrm{mg} / \mathrm{mL})$} \\
\cline { 2 - 5 } & 0.5 & 1.0 & 1.5 & 2.0 \\
\hline P-HW & $53.78 \pm 0.20^{\mathrm{bD}}$ & $68.92 \pm 0.20^{\mathrm{bC}}$ & $78.62 \pm 0.30^{\mathrm{bB}}$ & $86.92 \pm 0.58^{\mathrm{bA}}$ \\
P-UA & $18.06 \pm 0.46^{\mathrm{eD}}$ & $39.38 \pm 0.12^{\mathrm{dC}}$ & $49.20 \pm 0.35^{\mathrm{dB}}$ & $53.85 \pm 0.12^{\mathrm{dA}}$ \\
P-EAS & $39.38 \pm 0.46^{\mathrm{cD}}$ & $42.63 \pm 0.20^{\mathrm{cC}}$ & $54.12 \pm 0.12^{\mathrm{cB}}$ & $60.69 \pm 0.12^{\mathrm{cA}}$ \\
P-EAV & $31.27 \pm 0.35^{\mathrm{dD}}$ & $33.40 \pm 0.12^{\mathrm{eC}}$ & $42.90 \pm 0.12^{\mathrm{eB}}$ & $52.26 \pm 0.23^{\mathrm{eA}}$ \\
Acarbose & $75.83 \pm 0.12^{\mathrm{aD}}$ & $79.81 \pm 0.30^{\mathrm{aC}}$ & $82.94 \pm 0.12^{\mathrm{aB}}$ & $91.70 \pm 0.23^{\mathrm{aA}}$ \\
\hline
\end{tabular}

P-HW, crude polysaccharide fraction extracted by hot water; P-UA, crude polysaccharide fraction after ultrasonic-assisted extraction; P-EAS, crude polysaccharide fraction after enzyme-assisted extract using Shearzyme; P-EAV, crude polysaccharide fraction after enzyme-assisted extraction using Viscozyme.

Data are expressed as the mean \pm standard deviation $(n=3)$. Values with different small letters in the same column are significantly different $(\mathrm{P}<0.05)$. Values with different capital letters in the same row are significantly different $(\mathrm{P}<0.05)$. 
TABLE 3. Retarding effect of crude polysaccharide fractions extracted from $C$. sinensis on dialysis membrane transport of glucose.

\begin{tabular}{l|c|c|c|c|c|c|c|c}
\hline \multirow{2}{*}{ Fraction } & \multicolumn{7}{c}{ Dialysis time (min) } \\
\cline { 2 - 10 } & \multicolumn{2}{|c}{30} & \multicolumn{2}{c}{60} & \multicolumn{2}{c}{90} & \multicolumn{2}{c}{120} \\
\cline { 2 - 10 } & $\begin{array}{c}\text { Glucose } \\
\text { in dialysate } \\
(\mathrm{mg} / 100 \mathrm{~mL})\end{array}$ & $\begin{array}{c}\text { GRI } \\
(\%)\end{array}$ & $\begin{array}{c}\text { Glucose } \\
\text { in dialysate } \\
(\mathrm{mg} / 100 \mathrm{~mL})\end{array}$ & $\begin{array}{c}\text { GRI } \\
(\%)\end{array}$ & $\begin{array}{c}\text { Glucose } \\
\text { in dialysate } \\
(\mathrm{mg} / 100 \mathrm{~mL})\end{array}$ & $\begin{array}{c}\text { GRI } \\
(\%)\end{array}$ & $\begin{array}{c}\text { Glucose } \\
\text { in dialysate } \\
(\mathrm{mg} / 100 \mathrm{~mL})\end{array}$ & $\begin{array}{c}\text { GRI } \\
(\%)\end{array}$ \\
\hline Control & $6.08 \pm 0.50^{\mathrm{a}}$ & - & $16.18 \pm 1.39^{\mathrm{a}}$ & - & $22.38 \pm 2.61^{\mathrm{a}}$ & - & $27.87 \pm 1.76^{\mathrm{a}}$ & - \\
CMC & $5.28 \pm 0.38^{\mathrm{c}}$ & $13.16 \pm 0.56^{\mathrm{a}}$ & $7.74 \pm 0.59^{\mathrm{d}}$ & $52.16 \pm 0.63^{\mathrm{b}}$ & $10.95 \pm 1.57^{\mathrm{e}}$ & $51.07 \pm 1.22^{\mathrm{a}}$ & $18.07 \pm 2.56^{\mathrm{d}}$ & $35.16 \pm 2.23^{\mathrm{a}}$ \\
P-HW & $5.45 \pm 0.63^{\mathrm{b}}$ & $10.36 \pm 0.98^{\mathrm{c}}$ & $13.85 \pm 1.41^{\mathrm{b}}$ & $14.40 \pm 0.96^{\mathrm{d}}$ & $16.29 \pm 2.36^{\mathrm{c}}$ & $27.21 \pm 4.52^{\mathrm{c}}$ & $20.74 \pm 0.91^{\mathrm{c}}$ & $25.58 \pm 1.78^{\mathrm{b}}$ \\
P-UA & $5.47 \pm 1.23^{\mathrm{b}}$ & $10.03 \pm 1.00^{\mathrm{cd}}$ & $11.75 \pm 4.60^{\mathrm{c}}$ & $47.50 \pm 2.20^{\mathrm{c}}$ & $18.78 \pm 9.65^{\mathrm{b}}$ & $16.09 \pm 7.18^{\mathrm{d}}$ & $23.22 \pm 1.08^{\mathrm{b}}$ & $16.68 \pm 1.52^{\mathrm{c}}$ \\
P-EAS & $5.32 \pm 0.50^{\mathrm{c}}$ & $12.50 \pm 0.23^{\mathrm{b}}$ & $8.11 \pm 1.05^{\mathrm{d}}$ & $63.76 \pm 1.12^{\mathrm{a}}$ & $14.1 \pm 1.82^{\mathrm{d}}$ & $37.00 \pm 2.05^{\mathrm{b}}$ & $20.70 \pm 1.46^{\mathrm{c}}$ & $25.73 \pm 2.65^{\mathrm{b}}$ \\
P-EAV & $5.48 \pm 0.45^{\mathrm{b}}$ & $9.87 \pm 0.02^{\mathrm{d}}$ & $7.85 \pm 1.17^{\mathrm{d}}$ & $51.48 \pm 2.02^{\mathrm{b}}$ & $11.36 \pm 1.60^{\mathrm{c}}$ & $49.24 \pm 3.45^{\mathrm{a}}$ & $20.19 \pm 1.16^{\mathrm{c}}$ & $27.56 \pm 3.25^{\mathrm{b}}$ \\
\hline
\end{tabular}

P-HW, crude polysaccharide fraction extracted by hot water; P-UA, crude polysaccharide fraction after ultrasonic-assisted extraction; P-EAS, crude polysaccharide fraction after enzyme-assisted extract using Shearzyme; P-EAV, crude polysaccharide fraction after enzyme-assisted extraction using Viscozyme; CMC, Carboxymethylcellulose.

Sodium azide solution containing glucose without the crude polysaccharide fraction was used as a control. GRI, Glucose retardation index. Data are expressed as the mean \pm standard deviation $(n=3)$. Values with different letters in the same column are significantly different $(\mathrm{P}<0.05)$.

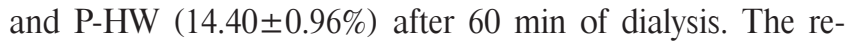
tardation effects of the sample decreased with longer dialysis time, but the GRI of P-HW increased steadily for up to $90 \mathrm{~min}$ of dialysis. After $120 \mathrm{~min}$ of dialysis, GRIs of crude polysaccharide fractions were 16.6-27.56\% and the GRI of CMC was $35.16 \%$. The GRI value of high dietary fiber powder from lime residues reached a maximum after 30 min of dialysis and decreased after a prolonged dialysis time [Peerajit et al., 2012], which was inconsistent with our results. This discrepancy may be due to differences in physical characteristics, such as water holding capacity, gelling property, and the viscosity of the solution. Crude polysaccharide fractions showed higher inhibitory effects on glucose diffusion compared to the control, although crude polysaccharide fractions retarded glucose diffusion less than CMC. A previous study showed that the delay of glu- cose diffusion and absorption by fiber is affected by viscosity of the intestinal digesta [Edwards et al., 1987] and that viscous polysaccharides may inhibit the intestinal uptake of nutrients by augmenting the apparent thickness of the unstirred water layer [Dongowski, 2007]. Based on these results, crude polysaccharide fractions, particularly P-EAS and P-EAV, are likely to dissolve and create network linkages in water, thereby retarding glucose diffusion and preventing glucose absorption in the gastrointestinal tract.

\section{Inhibitory effect of crude polysaccharides on bile acid diffusion}

Table 4 presents the effects of crude polysaccharide fractions extracted from $C$. sinensis by different methods on bile acid diffusion relative to the effects of $\mathrm{CMC}$ and a control

TABLE 4. Retarding effect of crude polysaccharide fractions extracted from C. sinensis on dialysis membrane transport of bile acid.

\begin{tabular}{|c|c|c|c|c|c|c|c|c|}
\hline \multirow{3}{*}{ Fraction } & \multicolumn{8}{|c|}{ Dialysis time (h) } \\
\hline & \multicolumn{2}{|c|}{0.5} & \multicolumn{2}{|c|}{1} & \multicolumn{2}{|c|}{2} & \multicolumn{2}{|c|}{5} \\
\hline & $\begin{array}{c}\text { Bile acid } \\
\text { in dialysate } \\
(\mu \mathrm{mol} / \mathrm{L})\end{array}$ & $\begin{array}{l}\text { BRI } \\
(\%)\end{array}$ & $\begin{array}{c}\text { Bile acid } \\
\text { in dialysate } \\
(\mu \mathrm{mol} / \mathrm{L})\end{array}$ & $\begin{array}{l}\text { BRI } \\
(\%)\end{array}$ & $\begin{array}{c}\text { Bile acid } \\
\text { in dialysate } \\
(\mu \mathrm{mol} / \mathrm{L}) \\
\end{array}$ & $\begin{array}{l}\text { BRI } \\
(\%)\end{array}$ & $\begin{array}{c}\text { Bile acid } \\
\text { in dialysate } \\
(\mu \mathrm{mol} / \mathrm{L}) \\
\end{array}$ & $\begin{array}{l}\text { BRI } \\
(\%)\end{array}$ \\
\hline Control & $184.7 \pm 11.6^{\mathrm{a}}$ & - & $300.9 \pm 5.4^{\mathrm{a}}$ & - & $396.6 \pm 16.7^{\mathrm{a}}$ & - & $503.9 \pm 5.6^{\mathrm{a}}$ & - \\
\hline $\mathrm{CMC}$ & $111.3 \pm 1.5^{c}$ & $39.7 \pm 0.5^{\mathrm{a}}$ & $176.3 \pm 7.0^{c}$ & $41.5 \pm 4.5^{\mathrm{a}}$ & $203.7 \pm 5.7^{c}$ & $49.6 \pm 2.8^{\mathrm{a}}$ & $247.0 \pm 8.1^{\mathrm{d}}$ & $59.3 \pm 5.8^{\mathrm{a}}$ \\
\hline P-HW & $174.7 \pm 10.0^{\mathrm{ab}}$ & $5.4 \pm 2.5^{c}$ & $273.7 \pm 8.7^{\mathrm{a}}$ & $9.0 \pm 4.9^{c}$ & $356.3 \pm 11.0^{\mathrm{b}}$ & $10.2 \pm 1.8^{\mathrm{b}}$ & $457.0 \pm 7.2^{\mathrm{c}}$ & $9.1 \pm 2.2^{\mathrm{b}}$ \\
\hline P-UA & $181.7 \pm 3.2^{\mathrm{ab}}$ & $2.2 \pm 1.4^{\mathrm{c}}$ & $281.8 \pm 53.2^{\mathrm{a}}$ & $5.7 \pm 2.8^{c}$ & $380.8 \pm 7.7^{\mathrm{ab}}$ & $4.0 \pm 1.7^{c}$ & $481.0 \pm 5.6^{\mathrm{b}}$ & $4.6 \pm 2.1^{c}$ \\
\hline P-EAS & $179.3 \pm 14.6^{\mathrm{ab}}$ & $3.2 \pm 2.7^{\mathrm{c}}$ & $281.3 \pm 18.9^{\mathrm{a}}$ & $6.4 \pm 3.8^{c}$ & $367.3 \pm 10.5^{b}$ & $7.4 \pm 1.9^{b}$ & $451.7 \pm 19.4^{c}$ & $10.3 \pm 2.4^{b}$ \\
\hline P-EAV & $164.3 \pm 11.4^{b}$ & $11.4 \pm 4.1^{b}$ & $208.3 \pm 8.1^{\mathrm{b}}$ & $30.9 \pm 6.7^{b}$ & $374.0 \pm 11.4^{\mathrm{b}}$ & $5.6 \pm 2.5^{\mathrm{bc}}$ & $477.0 \pm 6.0^{\mathrm{b}}$ & $5.4 \pm 1.9^{c}$ \\
\hline
\end{tabular}

P-HW, crude polysaccharide fraction extracted by hot water; P-UA, crude polysaccharide fraction after ultrasonic-assisted extraction; P-EAS, crude polysaccharide fraction after enzyme-assisted extract using Shearzyme; P-EAV, crude polysaccharide fraction after enzyme-assisted extraction using Viscozyme; CMC, Carboxymethylcellulose

Sodium azide solution containing taurocholic acid without the crude polysaccharide fraction was used as a control. BRI, bile acid retardation index. Data are expressed as the mean \pm standard deviation $(n=3)$. Values with different letters in the same column are significantly different $(P<0.05)$. 
(without crude polysaccharide fraction). Taurocholic acid concentrations in the dialysate containing crude polysaccharide fractions ranged from $164.3 \pm 11.4-181.7 \pm 3.2 \mu \mathrm{mol} / \mathrm{L}$ after $30 \mathrm{~min}$, to $451.7 \pm 19.4-481.0 \pm 5.6 \mu \mathrm{mol} / \mathrm{L}$ after $5 \mathrm{~h}$. Taurocholic acid levels of the control and CMC in the dialysate were $184.7 \pm 11.6$ and $111.3 \pm 1.5 \mu \mathrm{mol} / \mathrm{L}$ after $30 \mathrm{~min}$ of dialysis, and $503.9 \pm 5.6$ and $247.0 \pm 8.1 \mu \mathrm{mol} / \mathrm{L}$ after $5 \mathrm{~h}$ of dialysis, respectively. Compared to the control, crude polysaccharide fractions reduced the amount of taurocholic acid that transferred into the dialysate, but only P-EAS significantly prevented the diffusion of bile acid out of the dialysis membrane.

The BRIs of crude polysaccharide fractions ranged from $2.2-11.4 \%$ after dialysis for $30 \mathrm{~min}$. P-EAV showed the highest BRI value, which was however much lower than that of CMC (39.7\%). The BRIs of P-EAS and CMC steadily increased during dialysis, with the BRIs of CMC and ASP being 59.6\% and $10.3 \%$, respectively, after $5 \mathrm{~h}$ of dialysis. In contrast, most samples, except of P-EAS, showed the maximum BRI after dialysis for 1 or $2 \mathrm{~h}$, and the BRIs of P-HW, P-UA, and P-EAV were $9.0 \%, 5.7 \%$, and $30.9 \%$, after dialysis for $1 \mathrm{~h}$ respectively. Water-soluble dietary fibers produced from Chinese cabbage and buckwheat hulls by enzymatic hydrolysis also showed greater bile acid inhibitory effects than CMC [Im \& Yoon, 2015; Park \& Yoon, 2015]. In the present study, crude polysaccharide fractions showed slight absorption inhibitory effects and these observations are not consistent with those made in the previous studies.

\section{CONCLUSIONS}

In the presented study, we compared the antioxidant activity, $\alpha$-amylase inhibitory activity, and retarding effects on dialysis membrane transport of glucose and bile acid of crude polysaccharide fractions extracted from $C$. sinensis using four extraction methods. Data from this study demonstrated the feasibility of producing polysaccharides with biological activity. Especially, the crude polysaccharide (P-HW) extracted by hot-water showed not only high yield but also DPPH and ABRS radical scavenging activities and $\alpha$-amylase inhibitory activity. In addition, P-HW effectively hindered outward diffusion of glucose and bile acid through the dialysis membrane. Therefore, the crude polysaccharide fractions from $C$. sinensis are a practical new material with antioxidant activity, antidiabetic activity, and hypoglycemic effect that may be used in the food industry to prepare functional foods and nutraceutical products. It is undoubtedly comprehensible that a more detailed investigation for producing functional polysaccharides on a larger scale is needed to prove its values.

\section{RESEARCH FUNDING}

This work was supported by the 2017 Yeungnam University Research Grant.

\section{CONFLICT OF INTERESTS}

Authors declare no conflict of interests.

\section{REFERENCES}

1. Bartels D., Baumann A., Maeder M., Geske T., Heise E.M., Schwartzenberg K., Classen B., Evolution of plant cell wall: Arabinogalactan-proteins from three moss genera show structural differences compared to seed plants. Carbohydr. Polym., 2017, 163, 227-235.

2. Boyd G.S., Eastwood M.A., MacLean N., Bile acids in the rat: studies in experimental occlusion of the bile duct. J. Lipid Res., 1966, 7, 83-94.

3. Chen J.J., Zhang T., Jiang B., Mu W.M., Miao M., Characterization and antioxidant activity of Ginkgo biloba exocarp polysaccharides. Carbohydr. Polym., 2012, 87, 40-45.

4. Dongowski G., Interactions between dietary fibre-rich preparations and glycoconjugated bile acids in vitro. Food Chem., 2007, 104, 390-397.

5. Edwards C.A., Blackburn N.A., Craigen L., Davison P., Tomlin J., Sugden K., Johnson I.T., Read N.W., Viscosity of food gums determined in vitro related to their hypoglycemic actions. Am. J. Clin. Nutr., 1987, 46, 72-77.

6. Fan T., Hu J.G., Fu L.D., Zhang L.J., Optimization of enzymolysis-ultrasonic assisted extraction of polysaccharides from $\mathrm{Mo}$ mordica charabia L. by response surface methodology. Carbohydr. Polym., 2015, 115, 701-706.

7. Fu L., Chen H., Dong P., Zhang X., Zhang M., Effects of ultrasonic treatment on the physicochemical properties and DPPH radical scavenging activity of polysaccharides from mushroom Inonotus obliquus. J. Food Sci., 2010, 75, C322-327.

8. Gulbrandsen T.A., Johnsen I.A., Opedal M.T., Toven K., Øyaas K., Pranovich A., Mikkola J.P., Hoff B.H., Extracting hemicelluloses from softwood and bagasse as oligosaccharides using pure water and microwave heating. Cell. Chem. Technol., 2015, 49, 117-126.

9. He P., Li F., Huang L., Xue D., Liu W., Xu C., Chemical characterization and antioxidant activity of polysaccharide extract from spent mushroom substrate of Pleurotus eryngii. J. Taiwa Inst. Chem. Eng., 2016, 69, 48-53.

10. Horii S., Fukase H., Matsuo T., Kameda Y., Asano N., Matsui K., Synthesis and alpha-D-glucosidase inhibitory activity of $\mathrm{N}$-substituted valiolamine derivatives as potential oral antidiabetic agents. J. Med. Chem., 1986, 29, 1038-1046.

11. Hsu H.K., Yang Y.C., Hwang J.H., Hong S.J., Effects of Toona sinensis leaf extract on lipolysis in differentiated 3T3-L1 adipocytes. Kaohsiung J. Med. Sci., 2003, 19, 385-390.

12. Im H.J., Yoon K.Y., Production and characterization of alcohol-insoluble dietary fibre as a potential source for functional carbohydrates produced by enzymatic depolymerisation of buckwheat hull. Czech J. Food Sci., 2015, 33, 449-457.

13. Kelly G.S., Larch arabinogalactan: clinical relevance of a novel immune-enhancing polysaccharide. Altern. Med. Rev., 1999, 4, 96-103.

14. Kim M.H., Kim J.M., Yoon K.Y., Effects of blanching on antioxidant activity and total phenolic content according to type of medicinal plants. Food Sci. Biotechnol., 2013, 22, 817-823.

15. Li H.L., Chai Z., Shen G.X., Li C.Y., Polyphenol profiles and antioxidant properties of ethanol extracts from Osmanthus fragrans (Thunb.) Lour. flowers. Pol. J. Food Nutr. Sci., 2017, 67, 317-325. 
16. Li X., Wang L., Effects of extraction method on structure and antioxidant activity of Hohenbuehelia serotina polysaccharides. Int. J. Biol. Macromol., 2016, 83, 270-276.

17. Lin C.L., Wang C.C., Chang S.C., Inbaraj B.S., Chen B.H., Antioxidative activity of polysaccharide fractions isolated from Lycium barbarum Linnaeus. Int. J. Biol. Macromol., 2009, 45, 146-151.

18. Liu H.M., Wang F.Y., Liu Y.L., Hot-compressed water extraction of polysaccharides from soy hulls. Food Chem., 2016, 202, 104-109.

19. Luo H., Wang F., Bai Y., Chen T., Zheng W., Selenium nanoparticles inhibit the growth of HeLa and MDA-MB-231 cells through induction of S phase arrest. Colloid. Surface. B., 2012, 94, 304-308.

20. Luo X.D., Wu S.H., Ma Y.B., Wu D.G., Limonoids and phytol derivatives from Cedrela sinensis. Fitoterapia, 2000, 71, 492-496.

21. Miller G.L., Use of dinitrosalicylic acid reagent for determination of reducing sugar. Anal. Chem., 1959, 32, 426-428.

22. Oh M.H., Jang H.L., Lim Y.J., Yoon K.Y., Antioxidant activities of Cedrela sinensis hydrolysates prepared using various enzymes. Korean J. Food Sci. Technol., 2015, 47, 413-418.

23. Oh M.H., Yoon K.Y., Biological activity of water-soluble polysaccharides from Cedrela sinensis according to extraction methods. Korean J. Food Sci. Technol., 2017, 49, 215-221.

24. Ou S., Kwok K.C., Li Y., Fu L., In vitro study of possible role of dietary fiber in lowering postprandial serum glucose. J. Agr. Food Chem., 2001, 49, 1026-1029.

25. Pan L., Wang J., Ye X., Zha X., Luo J., Enzyme-assisted extraction of polysaccharides from Dendrobium chrysotoxum and its functional properties and immunomodulatory activity. LWT-Food Sci. Technol., 2015, 60, 1149-1154.

26. Park J.C., Yu Y.B., Lee J.H., Choi J.S., Ok K.D., Phenolic compounds from the rachis of Cedrela sinensis. Kor. J. Pharmacogn., 1996, 27, 219-223.

27. Park S.Y., Yoon K.Y., Enzymatic production of soluble dietary fiber from the cellulose fraction of Chinese cabbage waste and potential use as a functional food source. Food Sci. Biotechnol., 2015, 24, 529-535.

28. Peerajit P., Chiewchan N., Devahastin S., Effects of pretreatment methods on health-related functional properties of high dietary fibre powder from lime residues. Food Chem., 2012, 132, 1891-1898.

29. Rout S., Banerjee R., Free radical scavenging, anti-glycation and tyrosinase inhibition properties of a polysaccharide fraction isolated from the rind from Punica granatum. Bioresour. Technol., 2007, 98, 3159-3163,

30. Sangeethapriya M., Siddhuraju P., Health related functional characteristics and antioxidant potential of mucilage (dietary fiber) from Zizyphus mauritiana fruits. Food Sci. Hum. Wellness, 2014, 3, 79-88.

31. Shalaby E.A., Shanab S.M.M., Comparison of DPPH and ABTS assays for determining antioxidant potential of water and methanol extracts of Spirulina platensis. Indian J. Geo. Mar. Sci., 2013, 42, 556-564.

32. Shori A.B., Screening of antidiabetic and antioxidant activities of medicinal plants. J. Intergr. Med., 2015, 13, 297-304.

33. Telagari M., Hullatti K., In-vitro $\alpha$-amylase and $\alpha$-glucosidase inhibitory activity of Adiantum caudatum Linn. and Celosia argentea Linn. extracts and fractions. Indian J. Pharmacol., 2015, 47, 425-429.

34. Wang C., Chen Y., Hu M., Ding J., Xu C., Wang R., In vitro antioxidant activities of the polysaccharides from Tricholoma lobayense. Int. J. Biol. Macromol., 2012a, 50, 534-539.

35. Wang Y., Mao.F, Wei X., Characterization and antioxidant activities of polysaccharides from leaves, flowers and seeds of green tea. Carbohydr. Polym., 2012b, 88, 146-153.

36. Yin X., You Q., Jiang Z., Zhou X., Optimization for ultrasonicmicrowave synergistic extraction of polysaccharides from Cornus officinalis and characterization of polysaccharides. Int. J. Biol. Macromol., 2016, 83, 226-232.

37. Zhu Z., Dong F., Liu X., Lv Q., Yang Y., Liu F., Chen L., Wang T., Wang Z., Zhang Y., Effects of extraction methods on the yield, chemical structure and anti-tumor activity of polysaccharides from Cordyceps gunnii mycelia. Carbohydr. Polym., 2016, 140, 461-471.

Submitted: 9 June 2017. Revised: 2 August and 12 December 2017. Accepted: 14 December 2017. Published on-line: 28 March 2018. 